\title{
The Structural Logic of the Holistic Governance and Its Respond to Political Fragmentation
}

\author{
Tang Renwu ${ }^{1}$ Zhao Guoqin $^{2}$ \\ ${ }^{1,2}$ School of Management, Beijing Normal University, Beijing, P.R.China 100875 \\ ( rwtang@bnu.edu.cn, bnuzgq@126.com)
}

\begin{abstract}
As a frontier research topic in the field of public management in the western countries in recent years, the rising of holistic governance was not only promoted directly by the marketization reform and the development of information technology, but also stimulated by the spread of individualism thoughts and the governance fragment left by which in the practical level in the period of New Public Management. Holistic governance oriented by the public needs, use coordination, integration and responsibility as mechanism, utilize information technology to integrate different level of governance, function of governance, public-private partnership, information system organically, increasingly facilitate the process of "from decentralized to centralized, from parts to the whole, and from fragmentation to integration". Also, holistic governance carries out the strategy in the way of coordination, integration and increasing closeness and mutual involvement in the level of procedures; and holistic governance lean on taking the advantage of diverse, flexible and inclusive relationship between social solidarity to deal with the highly fragmentized network structure with the growingly prominent complex, dynamic and diversity. As to the respond to the appeal of solving the problem of political fragment, holistic governance emphasize that for fulfilling the holistic coordination, establishment of toleration institution, separation and contingency, exchange and mutual dependency and also compromise or hybridity should be implemented contrary to different types of fragment.
\end{abstract}

Keywords: The Structural Logic, The Holistic Governance, Political Fragmentation

\section{Introduction}

How to achieve the good governance of public affairs has always been the core objective pursued by public administration. In order to realize this objective, the public administration circle has already been forced to repeatedly revise and perfect the knowledge construction of learning. Nevertheless, in the soul searching of paradigm, it seems that neither Burrell and Morgan's division of the public administration into functionalism, interpretivism, radical humanism and radical structuralism nor the five paradigms induced by Henry from the historical perspective has been able to foresee the speed of paradigm shift caused by the increasingly complex, dynamic and diversified social environment is so fast. During the past 20 years, in the major countries, whether in the theoretical researches, or in the practical reforms of public sector, new public management has been taken as one of the leading paradigms of public administration. However, new public management's blind pursuit of "efficiency" has weakened a good many core values of public administration such as fairness, justice, representativeness, public participation and so on, and in terms of organizational construction, new public management is totally ignorant of the fact that it is often unconsciously restricted by the short-term market value and operating performance, which makes government organizations more inclined to have the features of functional differentiation and major differentiation and also have the tendency of constantly intensifying the functional decomposition governance. As a result, holistic governance emerged as the times require. Oriented by the public needs, holistic governance uses coordination, integration and responsibility as mechanism, utilizes 
information technology to integrate different levels of governance, function of governance, public-private partnership and information system organically, increasingly facilitates the process that "from decentralized to centralized, from parts to the whole, and from fragmentation to integration".

Although the common technical rationality and tacit grand narrative can be found behind paradigm war and paradigm shift, in terms of the holistic governance theory of new governance theory, within the academic circle there are different viewpoints. Some scholars hold that "cooperation", which holistic governance focuses on, is an old issue which has been put into practice for a long time in countries like UK and Canada, therefore the holistic government is simply a revival of "cooperation", though its content is much more complicated. And some scholars argue that whether in theory or practice, the holistic governance theory will hopefully become the grand theory on governmental governance in $21^{\text {st }}$ century, therefore it deserves scholars' extensive researches. Then compared with "cooperation" or "joined-up government", what is the innovation of the structural logic of holistic governance? How can holistic governance regain the core values of public administration, change the hollow governments in different aspects, as well as prevent and correct political fragmentation? As values change, the arrangement modes of organizational structure will also change. Then what will the organizational innovation of public managerialism that corresponds to holistic governance be? I don't want to make any judgment in advance, and putting forward these questions is no more than to help discuss them.

\section{The Construction of Holistic Governance's Logic System}

On the basis of reflecting on and bridging the governance fragmentation and functional composition, both of which are caused by new public management, holistic governance has gradually constructed a series of comparatively integrated theoretical system.

With respect to traditional public administration and new public management's focus on governmental departments, the logic starting point of holistic governance takes the solution of people's livelihood as the core, and it takes satisfying the whole requirement of citizens as the dominant concept: "individual living practice is listed as the top priority of government governance and the research focus of 'government organization' is transferred to the solution of 'individual problem' "; what's more, oriented by prevention and result, while affirming the value of efficiency, holistic governance emphasizes the democratic values like justice, fairness and responsibility and pursues the multiple values like civil rights, popular sovereignty and public interest to fully demonstrate the publicity of public administration.

In terms of governance structure, on the basis of taking the satisfaction of the public holistic requirements as the assumption and presupposition, holistic governance intends to accomplish the necessary integration among government's various hierarchies and departments as well as that among public-private departments to form the network structure of service-oriented governments. Within the network structure, based on the emphasis of actors' right of discretion, there exists certain mutually dependent and relatively stable structure among actors, in which they communicate, coordinate and interact with each other. As a result, the individual behaviors in the network are different from the atomized individual behaviors in the market structure of new public management; based on common principle, the network's self-organization with reciprocal logic is also different from the order hierarchy in the hierarchic chain of traditional public administration but appears to have the state of flexible boundary, joint dynamics and mutual dependence. The maintenance of the relationship between actors in the network is also a cooperative relationship with mutual recognition but not simply the interest dispute. Government is an important actor in the network node, and its mission lies in transforming its roles according to the network's operation needs in order to maintain the high efficient running of the network. Through integrating and optimizing the network, holistic governance, which has close relationship with the network structure, will also combine the high level of public-private collaboration characteristic and the robust network management capabilities to realize the perfect trans-boundary cooperative services and give citizens more choices in service 
delivery options.

In the paradigm of holistic governance, its governance mechanism cannot be the power and authority in the paradigm of traditional public administration, nor can it be the price mechanism in the paradigm of new public management, but it is dependent on the cultivation and implementation of coordination mechanism, integration mechanism and trust and accountability mechanism.

Along with the complication of public problems, the number of cross-sector public issues has increased; coordination problems are once again emphasized and entrusted new era connotation. In the context of holistic governance, coordination refers to "in the aspects of information, cognition and decision, understanding necessity for mutual involvement, but precise action not yet defined". And this coordination mechanism should coordinate both the interest relationship between actors and the relationship between actors and the whole network. First of all, in the network structure of holistic governance, actors are possibly compatible with each other in objective distribution and solution formulation but also possibly collide with each other. Coordination mechanism commits itself to relieving the conflicts and strengthens the cohesion of the network structure in holistic governance through intensifying and shaping the common goal. As a result, coordination mechanism in holistic governance should first contain the value synergy coordination mechanism to create the synergy effect and try to reduce the uncertainty caused by interdependence. Second, information sharing is also an important part of the network coordination mechanism, and the information sharing system that can match holistic governance is indispensable. Last, the effective implementation of resource distribution based on value synergy and information sharing requires managers to choose appropriate actors and material types as well as to use various related resources like capital, personnel, professional knowledge, technology and information to participate in the network structure to deal with the complicated and wicked public problems.

Integration mechanism is another important mechanism in holistic governance. In the context of holistic governance, integration refers to "in the level of execution, implementation and practical action, through building fully seamless programs, realized the highest level of holistic governance". Problems like the fragmentation of policy content and the departmentalization of policy interest are not mainly caused by policy content but decided by the system which formulates the policy. Realizing policy compatibility through integrating policies has passed into history, so hunting new integration means is the reform direction of holistic governance. Holistic governance tries to construct a three-dimensional integration model through the integration of governance hierarchy, the integration of governance functions and the integration between public and private departments. Any public problem can locate its position in this model, which means the relatively effective solution of any complicated and troublesome problem can only be done through satisfying the requirements: putting the problem into the multi-dimensional structure, using multi-approaches and multiparty participation.

The main reason why trust and accountability mechanism has become one of the holistic governance mechanisms lies in that the endogenic network governance structure of holistic governance is a structure within which various organizations are interdependent: there doesn't exist a superior-subordinate relationship between organizations, and when lacking the leadership of legal authority and the inducement of price mechanism, different actors and organizations can unite to solve problems together. Trust is a kind of agent relationship, above which clients act on the risk of their self-interest, but only when clients are, to a varying degree, self-confident that they can depend on the agent through judging from anticipated agent behaviors and self-interest satisfaction can trust appear. Integrity's sense of responsibility mainly focus on how to elevate effectiveness and item responsibility to the highest position, ensuring that honesty and efficiency responsibility will not collide with this objective as well as using output to define what should be effectively completed to make honesty and efficiency responsibility serve effectiveness and item responsibility. What's more, some scholars who study holistic governance have also listed the ways of acquiring and maintaining trust as well as hunting responsibility. 


\section{The Strategy Development Logic of Holistic Governance}

In the process orientation of holistic governance's strategy development and in the process logic of holistic governance, Perri 6 in 2002 divided holistic governance into two phases: coordination and integration. As the first phase of process orientation, coordination makes government organizations develop from fragmentation to solidarity and constructs the integration structure. Coordination is the pioneer of integration and there exists a close relationship between them: "This is the problem of integration without coordination, which can lead to messy and time-wasting duplications of efforts", and "the failure to coordinate can undermine integration". However, whether coordination or integration, they are both faced with threefold obstacles: (1) administrators' understanding of the scope of coordination and integration as well as legislators and judicial officers' influence on coordination and integration, (2) different management organizations will obstruct the horizontal teamwork work within the same jurisdiction, (3) the vertical integration between the central government and regional governments. To solve these obstacles requires more comprehensive coordination and deeper integration. As a result, Perri 6 in 2004 expanded the two phases to coordination, integration as well as Increasing closeness and mutual involvement (as showed in Table 1) which is a cooperation mode owning better high consistency and close-type than integration. Through the deep cooperation in this third phase, government organizations will gradually realize strategic alliance, alliance or mergence.

\begin{tabular}{|c|c|c|}
\hline $\begin{array}{l}\text { Category of } \\
\text { relationship }\end{array}$ & $\begin{array}{l}\text { Type of } \\
\text { relationship } \\
\text { between entities }\end{array}$ & Definition \\
\hline coordination & $\begin{array}{l}\text { Taking into } \\
\text { account; dialogue; } \\
\text { joint planning }\end{array}$ & $\begin{array}{l}\text { Strategy development considers the impact of/on others; exchange } \\
\text { of information; temporary joint planning or joint working }\end{array}$ \\
\hline integration & $\begin{array}{lr}\text { Joint } & \text { working; } \\
\text { joint } & \text { venture; } \\
\text { satellite; } & \text { strategic } \\
\text { alliance; } & \text { union; } \\
\text { merger } & \end{array}$ & $\begin{array}{l}\text { Temporary collaboration; long-term joint planning and joint } \\
\text { working on major project core to the mission of at least on } \\
\text { participating entity; separate entity, jointly owned, created to serve } \\
\text { as integrative mechanism; long-term joint planning and working on } \\
\text { issues core to the mission of at least one participating entity formal } \\
\text { administrative unification, maintaining some distinct identities } \\
\text { fusion to create a new structure with a single new identity }\end{array}$ \\
\hline $\begin{array}{l}\text { Increasing } \\
\text { closeness and } \\
\text { mutual } \\
\text { involvement }\end{array}$ & $\begin{array}{l}\text { Satellite; } \\
\text { Strategic } \\
\text { alliance; Union; } \\
\text { Merger }\end{array}$ & $\begin{array}{l}\text { Long-term joint planning and working on issues core to the } \\
\text { mission of at least one participating entity; Formal } \\
\text { administrative unification, maintaining some distinct } \\
\text { identities; Fusion to create a new structure with a single new } \\
\text { identity. }\end{array}$ \\
\hline
\end{tabular}

Source: Joined-up Government in the Western World in Comparative Perspective: a preliminary literature review and exploration. Journal of public administration research and theory, 2004, 14(2): 108

Table 1: The three phases of holistic governance and possible types of strategy

Judged from the general logic, in holistic governance, failure in the previous phase will perhaps directly lead to the failure in the following phase. In fact, the operation of holistic governance is just like the roundtable forum. Coordination means through various parties' efforts making all the parties that are faced with troublesome problems and fragmentation forget each other's past misdeeds and obviate dissents to sit at the roundtable; at the moment, what they need to do is create the communication language together and discuss together the importance of the focused issues and agreed issues to realize friendly communication and sincere dialogue; all these can create good conditions for integration. And integration refers to that all participants at the round table together discuss the content and order of issues, jointly decide the mutual coordinating way between policy objective and means, reach the policy execution strategy and route unitedly as well as together make clear rights and obligations of all parties. Increasing closeness and mutual involvement refers to realizing the comprehensive, long-run and deep cooperation and the possibility and tendency of next or several roundtable forums.

In terms of researches on organizational relationship, many western scholars use some 
rather classic words to describe and interpret the uncoordinated relationship between organizations such as "tragedy of the commons, prisoners' dilemma and collective action dilemmas", "the conflict between individual rationality and collective rationality" and so on. On how to deal with these uncoordinated relationships, Vincent A. Ostrom put forward "polycentrism" and "compound republic", while James McGill Buchanan came up with "competitive federalism" as the response mechanism; when emphasizing the possibility of self-governing public affairs outside the pale of organization and market, Elinor Ostrom advanced "self organization and governance" theory.

Fragmental organizations and the coordination between them have appeared to be obviously complicated and diversified. From the dimension of social regulation to that of social integration, Perri 6 divided fragmental organizations into Fatalism's Isolate, Hierarchy, Individualism and Communitarianism's Enclave. On coordinating the organization orientation relationship, scholars on holistic governance assume that it requires defining settlements aiming to social organizations to make them know about how organization relationships operate. As far as the concept of settlement is concerned, any arrangement that aims at maintaining system survival and that is able to repress unrest can be regarded as settlement, for instance, social and political reconciliation can create the coexistent practical structure; on dealing with social organizations with cognitive differences and cultural biases, the settlement is bridging or via-media.

As far as organization relationship orientation is concerned, the complexity, diversity and dynamic of the relationship between organizations have become inevitable. When facing the highly fragmental organization relationship, governments should adopt the diversified, flexible and tolerant coordinating means instead of using law as the only means. Just as what Perri 6 has said, considering the diversity of organizations, coordination should be used to help facilitate the mutual union between organizations; in order to avoid coordination's monotony, the diversified and flexible coordinating means should be adopted.

\section{The Necessary Argumentation of Holistic Governance: the Settlements of Fragmentation}

Just as what advocates of holistic governance theory have said, the fundamental purpose of coordination is to overcome government organization's fragmentation and to facilitate the cooperation and union between organizations. Fragmentation can be mainly divided into malign fragment and benign fragment. The existence of differences between fragmental organization forms is totally decided by the differences in organizational culture, concept and institution, and the organic coordination between organizations should also be diversified instead of taking the single coordinating way. Aiming at the above fragmentation and fragmental organization, there are two ways: obviating dissents and seeking common ground. The so-called obviating dissents refers to educing dissimilarity between solidarities, that is to say, fully restricting the chance of different organizations' mutual conflicts and excluding the possibility of mutual harm; its operating mode is like this: from soft persuasion to semi-rigid waning and then to strong punishment. The so-called seeking common ground means producing internal similarity within solidarities, namely, creating reciprocal inducement to make organizations willing to communicate or cooperate with each other and thus mutually integrate their internal motivation. Now according to the strategy development order of obviating dissents and seeking common ground:

The first one is to construct toleration of a specific set of institution, which means obviating dissents first and then seeking common ground to construct an institution which can be accepted by each other and mutually tolerated. It is the coordinating work of clumsy institution. Toleration of a specific set of institution is binding upon every social organization, thus no organization can propose a veto on the institution. In this institution there are definite regulations of obligation and accountability. This kind of toleration institution has better tolerance, the construction of which requires government organization as the sponsor. At the same time government organization should also become the peace-keeper and chastiser of institution violator: obviating dissents through coercive 
measures and then reaching an agreement by institutionalized means, which means that based on the principle of making concessions, all parties offer a concession to accept the neutral toleration institution to pursue the glorious future of government organization development.

The second one is separation and contingency, which refers to seeking common ground without obviating dissents. It is a settlement that reaches holistic governance through waiting, gradually changing and partly recharging. In the process of executing the settlement separation and overall change, holistic governance will encounter dilemmas like "collective action dilemmas", "free riding" and "tragedy of the commons". At this moment, it requires that some enthusiastic people are willing to provide public finance to once maintain the sustainability and transaction costs of cooperation so that in the mutual adjustment and mutual adaptation, all organizations can realize integration and fusion on the basis of keeping their relative independence to mold a multiple and tolerant organization.

The third one is exchange and mutual decency, which refers to without obviating dissents or seeking common ground. What this settlement needs to solve is the "sudden" conflicts and "chaos" between certain organizations. On the solution of this, what can be dependent on are enthusiastic services and honest communications provided by all kinds of organizations as well as the labor division through the reciprocal and freely interactive methods; on the basis of free interaction, the intervention and domination of strong power should be opposed. Thus it can be seen that the sponsor of this settlement is an intermediate organization that lies between government and market, and the implementation of this settlement requires relatively high sociality and spontaneity.

The last one is compromise and hybridity, which means obviating dissents without seeking common ground, namely, to seek the possibility of mutually making concessions and compromising with each other through self-restraint between organizations, as a result, the realized outcome is the bargaining one which is unable to form complete consistency or symmetry. Compromise and hybridity force government organizations to make a concession and require seeking a sort of coordinator handling dispute, conflict and dissension, making organizations bury the hatchet, relieve conflicts, abandon dissensions, and avoid zero-sum reforms to jointly pursue interest and increase performance.

It is noteworthy that because of the high changeability, complexity and unpredictability of fragmentation, troublesome problems and interwoven issues, the settlements of fragmentation and interwoven issues are far more than these four sorts. As a result, only by necessarily combining diversified and flexible settlements can the diversified, complex and unpredictable fragmentation be effectively dealt with and thus organic coordination and holistic integration can be realized.

\section{5 .Conclusions}

In theory, as a new paradigm in the field of pubic management, the rising of holistic governance is different from the new public management, which is from the angle economic and social to understand, and its background is the global economic integration and the required promoting efficiency, however, in some extent, holistic can be understood in the angle of technology. From the methodology, both the traditional bureaucratic system and the recent new public management paradigms both adopted the methodology of individualism, which lead to severe fragmentation and departmental centrism, and cannot fit with the complex, dynamic and diverse "real world", which triggered public discontent and anger. In contrast, the holistic governance discarded unilaterally attention of government, and with the help of the development of information technology in digital era, based on the thinking way of holism, through the training and consolidating the coordinate mechanism, integrative mechanism, trust and accountability mechanism in the network governance structure, which benefit of taking advantage of the powerful force formed by the comparative and exclusive resources of the public management with diversity and heterogeneity.

Any attempt of reform try to express the expect people hold to the revolution, and each new model itself shows that the new recognition the people hold to the problem of government. Also this this new model always tries to transform the anxiety and unsatisfied vague feeling of citizens to their government in 
to a specific causal relationship. It is necessary for us to understand the reason of problem in the complex political reforms; however, any attempt to structuralize the complex social and political institutions is inevitably too simple. As opposed to traditional public administration and new public management, the holistic governance theory holds the chance to become an important paradigm shift, however, it also facing immeasurable challenges, its defines, concepts, assumptions, strategies, feasibility need to go through extensive discussions, and the process may be long and controversial. Meanwhile, as a new paradigm of public administration, the holistic governance theory just provided one of the alternative schemes, without becoming a workable panacea in any time and any place. To build and improve its system construction could also be a long-term project. After all, the integration of new abilities, the reform of organizational culture and building the mutual trust relationship are require great patience. Successful institutional reform should be more like a gardener than an engineer or architect.

\section{Acknowledgment:}

Financed by Chinese National Social Science Fund Youth Project in 2012: Research on power spatial distribution institution of Chinese provincial government (12CGL085).

\section{References}

[1]Barzelay, M.Breaking Through Bureaucracy[M]. Berkeley: University of California Press, 2002.

[2] Christopher Pollitt. Joined-up Government: A Survey[J]. Political Studies Review, 2003(1):34-39.

[3] deLeon, L. \& Denhardt, R. The Political Theory of Reinvention [J]. Public Administration Review, 60(2):89-97.

[4] Frederickson, G. The Spirit of Public Administration[M]. San Francisco: Jossey-Bass Publishers, 1997.

[5] Henry, N. Paradigms of Public Administration[J]. Public Administration Review, 35 (4): 378 - 386.

[6] Hood, C. The Idea of Joined-up Government: A Historical Perspective[C]. In V. Bogdanor(ed), Joined-up Government British Academy Occasional Papers. Oxford: Oxford University Press,2005.
[7] Kettl, D. The Transformation of Governance: Public Administration for Twenty-first Century America[M]. Baltimore: Johns Hopkins University Press, 2002.

[8] March G \& J.Olsen. Organizing Political Life [J]. American Political Science Review. 1983(2): 281-296.

[9] Perri 6. Holistic Government[M]. London: Demos, 1997:45.

[10] Perri 6. Governing in the round: Strategies for Holistic Government[M]. London: Demos, 1999:24-25

[11] Perri 6. Diana Leat. Kimberly Seltzer and Gerry Stocker. Towards Holistic Governance: The New Reform Agenda[M]. York: Palgrave,2002.

[12] Perri 6, Joined-up Government in the Western World in Comparative Perspective: a preliminary literature review and exploration $[\mathrm{J}]$. Journal of public administration research and theory, 2004,14(2): 108

[13] Peters, G. Managing the Hollow State [J]. International Journal of Public Administration. 1994(17):739-756.

[14] Peter Laugharne. Towards Holistic Governance(Book Review)[J]. Democratization, 2004(3):164.

[15] Pollitt, C. Managerialism and Public Service: Cuts or Cultural Change in the 1990s[M]. Oxford: Blackwell,1993. 